\title{
Breast feeding, eczema, asthma, and hayfever
}

\author{
BRENT TAYLOR, JANE WADSWORTH, JEAN GOLDING, AND NEVILLE BUTLER \\ From the Child Health and Education Study, Department of Child Health, University of Bristol, Bristol, UK
}

SUMMARY The association of breast feeding with rates of atopic illness during the first five years of life was assessed in a national study of 13135 children studied during the first week and at age 5 years. Eczema was reported more often in children who had been breast fed; this relationship persisted even after allowance was made for social and family factors influencing the likelihood both of breast feeding and of eczema; the other factors most significantly associated with rates of eczema were parental history of eczema or asthma and advantaged family socioeconomic status. A similar, but less pronounced, positive association of breast feeding with reported hayfever became non-significant after adjustment for intervening factors. Rates of reported asthma were not influenced by breast feeding. "Any wheezing" including asthma was reported more often in children who had not been breast fed, but this association disappeared after adjustment for parental asthma and maternal smoking. Breast feeding does not appear to protect against these atopic diseases. The positive association with reported eczema might relate to accuracy of diagnosis or to associated influences not considered in the analysis; alternatively, it might be due to (recent) environmental contaminants crossing in breast milk, causing eczema in the child.

The role of breast feeding in the prevention of atopic diseases, eczema, hayfever, and asthma is a contentious issue. Studies showing benefit from breast feeding ${ }^{1-6}$ have been balanced by other studies showing no benefit. ${ }^{7-13}$ Similar confounding results have been seen when soya milk was given instead of cows' milk as a substitute for breast feeding: some surveys showed a reduced risk of eczema ${ }^{14}{ }^{15}$ but others showed no benefits. ${ }^{78 \text { 16-18 }}$

There has been little attempt in most of these studies to allow for differences in socioeconomic status of subjects breast feeding or bottle feeding. There may, for example, be social class differences in what rashes are interpreted as eczema. The situation is compounded for asthma by the recognised difficulties of making the diagnosis, particularly in very young children. ${ }^{19-21}$

In this paper we have investigated the relationships between infant feeding and reported atopic disorders in a national cohort of children, taking into consideration family, social, and other biological factors.

\section{Subjects and methods}

CHES (Child Health and Education Study) is a continuing survey of children studied during the first week of life in the British Births Survey. ${ }^{22}{ }^{23}$ The cohort originally included all children born in the United Kingdom between 5 and 11 April 1970 inclusive. In 1975 children were traced who had been born in that week and lived in England, Scotland, and Wales; 12743 subjects were interviewed out of a possible 16015 from the birth survey (79.6\%). At the five year home interview local health visitors gathered a wide range of social, family, and health data (over 500 items) using a structured questionnaire. The health visitors were provided with a booklet containing notes about the survey and details about how to conduct the interview, ask the individual questions, and complete the questionnaire. The parents (usually the mother) were asked:

(1) Whether the child had been breast fed, partly or wholly and for how long; duration of breast feeding was recorded as not breast fed at all, fed under one month, one to three months, or three months or longer.

(2) Whether or not the child had had eczema (not otherwise defined) at any time during the previous five years.

(3) Whether or not the child had had hayfever (not otherwise defined).

(4) Whether or not the child had had any episodes 95 
The interviewers were instructed not to mention the word asthma.

(5) The parents were then asked whether a diagnosis had been given to the child's wheezing. When the parents replied "asthma," this was recorded.

The following factors derived from the birth and five year interviews were included as control variables in multivariate analyses: maternal age (under 20 or older at the study child's birth), the child's birth weight ( $<$ or $\geqslant 2500 \mathrm{~g}$ ), birth rank (whether or not there were older siblings at age 5), health visitor's assessment of the home equipment (luxurious, well equipped or adequate, low, very low standard), maternal smoking (average number of cigarettes smoked regularly each day during pregnancy: none, $0-4,5-14, \geqslant 15$ ), parental history of asthma or eczema, or both, and the social index ${ }^{24}$ which is a composite assessment of socioeconomic status at 5 derived from indices of domestic crowding, parental education, tenure of accommodation, type of neighbourhood, and father's occupation. Factors were first selected on empirical grounds as being likely to contribute to the outcome being assessed. The final multivariate models used contained only those factors having the greatest influence.

Cases with missing information on any of the above variables (never more than 5\% for any variable and in most cases less than $1 \%$ ) were omitted from the analyses. Preliminary analyses included tabulations and chi squared statistics. For multivariate analyses, stepwise logistic regression ${ }^{25}$ was performed using the statistical package BMDP. ${ }^{28}$ The individual contribution of each factor and possible interactions in the multivariate analyses were assessed by the log likelihood chi square statistic.

\section{Results}

Overall, $12 \cdot 2 \%$ of the population were reported as ever having eczema, $4 \cdot 2 \%$ hayfever, $2 \cdot 0 \%$ asthma, and $21 \cdot 1 \%$ wheezing. Over half the children $(63.0 \%)$ were not breast fed; $16 \cdot 1 \%$ were breast fed for under a month, $10.0 \%$ for one or two months, and $10.9 \%$ for three months or longer. A parental history of asthma or eczema or both had only slight influence on rates of breast feeding; $40 \cdot 3 \%$ of those with a positive family history were breast fed compared with $36 \cdot 2 \%$ of those without.

Table 1 shows the way in which each of the atopic conditions varied with the factors, other than breast feeding, considered in the multivariate analyses. There was no consistent pattern of association with the different atopic conditions. For social index the relationship with reported eczema and hayfever was positive, there was a negative association when "any
Table 1 Social and biological associations of factors other than breast feeding, with eczema, hayfever, asthma, and any wheezing

\begin{tabular}{|c|c|c|c|c|}
\hline \multirow[b]{2}{*}{ Factor } & \multicolumn{4}{|c|}{ \% of children with reported: } \\
\hline & Eczema & Hayfever & Asthma & $\begin{array}{l}\text { Any } \\
\text { wheezing }\end{array}$ \\
\hline \multicolumn{5}{|l|}{ Social index. } \\
\hline Advantaged & $15 \cdot 6$ & $5 \cdot 3$ & 1.9 & $19 \cdot 3$ \\
\hline Average & $10 \cdot 9$ & $4 \cdot 4$ & $2 \cdot 4$ & $21 \cdot 1$ \\
\hline Disadvantaged & $9 \cdot 5$ & $3 \cdot 1$ & $1 \cdot 8$ & $22 \cdot 6$ \\
\hline \multicolumn{5}{|l|}{ Birthrank } \\
\hline Oldest/only at 5 & 12.9 & $6 \cdot 0$ & $2 \cdot 2$ & $19 \cdot 8$ \\
\hline Older siblings & $11 \cdot 9$ & $3 \cdot 4$ & $2 \cdot 0$ & $21 \cdot 5$ \\
\hline \multicolumn{5}{|l|}{ Home assessment } \\
\hline Luxurious or well equipped & $13 \cdot 7$ & $5 \cdot 0$ & $2 \cdot 1$ & $20 \cdot 0$ \\
\hline Adequate & $10 \cdot 8$ & $3 \cdot 7$ & $2 \cdot 1$ & $21 \cdot 7$ \\
\hline Low or very low standard & 6.8 & 3.0 & 1.6 & $26 \cdot 0$ \\
\hline \multicolumn{5}{|l|}{ Family history } \\
\hline Asthma or eczema or both & $17 \cdot 1$ & $7 \cdot 2$ & $3 \cdot 1$ & $24 \cdot 5$ \\
\hline Neither & 9.6 & $2 \cdot 8$ & 1.5 & $19 \cdot 0$ \\
\hline \multicolumn{5}{|l|}{ Mother's age } \\
\hline$<20$ & $11 \cdot 5$ & 3.9 & $1 \cdot 5$ & $21 \cdot 2$ \\
\hline$\geqslant 20$ & $12 \cdot 3$ & $4 \cdot 5$ & $2 \cdot 1$ & 20.8 \\
\hline \multicolumn{5}{|l|}{ Birthweight } \\
\hline$<2500_{\mathrm{g}}$ & $8 \cdot 8$ & $4 \cdot 2$ & 2.7 & 25.6 \\
\hline$\geqslant 2500 \mathrm{~g}$ & $12 \cdot 5$ & $4 \cdot 4$ & $2 \cdot 0$ & $20 \cdot 5$ \\
\hline \multicolumn{5}{|l|}{ Maternal smoking } \\
\hline Non-smoker & $13 \cdot 1$ & $4 \cdot 6$ & 1.7 & $18 \cdot 7$ \\
\hline 1-14 cigarettes/day & $11 \cdot 2$ & $4 \cdot 2$ & $2 \cdot 2$ & $22 \cdot 4$ \\
\hline$\geqslant 15$ cigarettes/day & $11 \cdot 8$ & $4 \cdot 0$ & $2 \cdot 9$ & $24 \cdot 6$ \\
\hline
\end{tabular}

wheezing" was considered, and no association with reported asthma. A similar discrepancy was seen ino relation to the health visitor's assessment of the home. equipment; a positive association with eczema and hayfever but a negative association with any wheezing and no obvious relationship with asthma.

Table 2 shows the proportions of children reported as having eczema, hayfever, asthma, and any wheezing according to the duration of breast feeding. For eczema and hayfever increasing duration of

Table 2- Effect of adjusting for social and biological influences on the relationship between breast feeding and eczema, hayfever, asthma, and any wheezing during the first five years

\begin{tabular}{|c|c|c|c|c|c|c|}
\hline & \multirow{2}{*}{$\begin{array}{l}\text { All } \\
\text { children }\end{array}$} & \multirow{2}{*}{$\begin{array}{l}\text { Never } \\
\text { started }\end{array}$} & \multicolumn{3}{|c|}{$\begin{array}{l}\text { Duration of breast } \\
\text { feeding (months) }\end{array}$} & \multirow[b]{2}{*}{$p$ value } \\
\hline & & & $t<1$ & 1,2 & $>3$ & \\
\hline Eczema (n) & 10886 & 6793 & 1821 & 1088 & 1184 & \\
\hline Unadjusted rate (\%) & $12 \cdot 2$ & $11 \cdot 1$ & $14 \cdot 1$ & 13.6 & $16 \cdot 1$ & $<0.001^{*}$ \\
\hline Adjusted rate (\%) & $12 \cdot 2$ & 11.4 & $13 \cdot 2$ & $13 \cdot 2$ & $14 \cdot 4$ & $<0.01 t$ \\
\hline Hayfever (n) & 10781 & 6737 & 1797 & 1078 & 1169 & \\
\hline Unadjusted rate $(\%)$ & $4 \cdot 2$ & 3.8 & $4 \cdot 2$ & $5 \cdot 5$ & 5.6 & $<0.001 *$ \\
\hline Adjusted rate (\%) & $4 \cdot 2$ & $4 \cdot 0$ & $3 \cdot 7$ & 4.9 & $5 \cdot 2$ & NSt \\
\hline Asthma (n) & 12608 & 7957 & 2038 & 1256 & 1363 & \\
\hline Unadjusted rate (\%) & $2 \cdot 0$ & $2 \cdot 2$ & 1.6 & 1.8 & $2 \cdot 1$ & NS* \\
\hline Any wheezing (n) & 10867 & 6796 & 1814 & 1076 & 1181 & \\
\hline Unadjusted rate (\%) & $21 \cdot 1$ & $22 \cdot 1$ & $20 \cdot 8$ & 19.7 & $17 \cdot 8$ & $<0.01^{*}$ \\
\hline Adjusted rate (\%) & $21 \cdot 1$ & $21 \cdot 7$ & $21 \cdot 0$ & $20 \cdot 1$ & 18.4 & NSt \\
\hline
\end{tabular}

"Chi square for trend.

tLogistic regression methods. 
breast feeding was associated with increased likelihood of illness. For asthma there was no significant association but for any wheezing a significant negative association; those breast fed longer had less wheezing reported. When allowance was made for other factors also associated with atopic conditions, however, the association between breast feeding and both hayfever and any wheezing became non-significant. A significant positive association persisted with eczema, however, even after allowing for other influences.

The significant influences on the conditions being assessed after adjustment for intervening factors are shown in table 3 in the order of significance of their contribution to the logistic regression analysis. The most significant factor in each was a history of asthma or eczema in a parent. Other factors differed, however; for eczema positive associations were found with advantaged social index and history of breast feeding; with hayfever, there was a strong association with the eldest child as well as with advantaged socioeconomic status; with reported wheezing, the other major significant factor was a history of maternal smoking during pregnancy.

Table 3 Factors influencing illness during the first five years in order of significance in logistic regression analyses

\begin{tabular}{|c|c|c|c|}
\hline Eczema & Hayfever & Asthma & Any wheezing \\
\hline \multicolumn{4}{|l|}{ Significant factors } \\
\hline $\begin{array}{l}\text { Parental history } \\
\text { eczema or } \\
\text { asthma or both }{ }^{* * *}\end{array}$ & $\begin{array}{l}\text { Parental history } \\
\text { asthma } * * *\end{array}$ & $\begin{array}{l}\text { Parental history } \\
\text { asthma *** }\end{array}$ & $\begin{array}{l}\text { Parental history } \\
\text { asthma *** }\end{array}$ \\
\hline Social index $* * *$ & Birth rank *** & Social index * & $\begin{array}{l}\text { Maternal } \\
\text { smoking *** }\end{array}$ \\
\hline $\begin{array}{l}\text { Breast feeding** } \\
\text { Home assessment } \\
\text { Birth weight * }\end{array}$ & Social index *** & & $\begin{array}{l}\text { Birth weight * } \\
\text { Birth rank * }\end{array}$ \\
\hline \multicolumn{4}{|l|}{ Non-significant factors } \\
\hline Mothers' age & Home assessment & Maternal smoking & Home assessment \\
\hline Birth rank & $\begin{array}{l}\text { Breast feeding } \\
\text { Mother's age } \\
\text { Birth weight }\end{array}$ & $\begin{array}{l}\text { Birth weight } \\
\text { Birth rank } \\
\text { Breast feeding } \\
\text { Home assessment }\end{array}$ & $\begin{array}{l}\text { Breast feeding } \\
\text { Social index }\end{array}$ \\
\hline
\end{tabular}

$\because p<<0.001$

$p<0.01$
$p<0.05$

\section{Discussion}

The results of this study suggest that breast feeding does not protect against atopic diseases. Indeed, for reported eczema, irrespective of possible confounding influences, there was a positive association. A similar trend, more eczema with breast feeding, has been suggested in other recent surveys. ${ }^{10}{ }^{1127}$ In these studies, one from Canada and the other two from England, the comparatively small numbers precluded a statistically significant difference. Although this association would appear to be a recent finding, perhaps indicating recent changes, the phenomenon may have existed unrecognised for decades, a possibility that analysis of previous national cohorts might show. If this is a recent phenomenon, however, it could be that some environmental contaminant has been transmitted to the child via the mother's milk. The organohalides are a possible suspect-the polychlorinated biphenyls in particular. ${ }^{28}$ These industrial chemicals, not normally excreted by man, gradually accumulate in fat with long term low level exposure. Lactation is the only way in which large amounts of such residues can be excreted. Taken in this form, such pollutants may have adverse effects on young children. Allergens crossing in breast milk are another possibility. ${ }^{27,}{ }^{20-32}$ Recent dietary changes such as increased consumption of processed foods may be contributing new allergens that are difficult for the maternal digestive system to render harmless to the child.

The contrasting associations of breast feeding on asthma and any wheezing shows the difficulties associated with the diagnosis of asthma and the manifestation of wheezing in childhood. No direct association was seen with reported asthma but there was a negative association with wheezing; this latter effect, however, was eliminated by allowing for social factors including maternal smoking.

All that wheezes is not asthma. The belief that wheezy bronchitis is but part of the asthmatic spectrum ${ }^{19}$ does not have universal agreement. ${ }^{21}$ The symptom of wheezing reflects asthma in many children, particularly in those with a family tendency "to have asthma." In addition wheezing often accompanies respiratory viral infections; up to $40 \%$ of children wheeze during their first year of life $^{33}$ 34-that is, have wheezy bronchitis. Minimal association of socioeconomic disadvantage with reported wheezing was shown in this study, although a strong association has been shown for reported bronchitis. ${ }^{35-37}$ These differential findings confirm the necessity of taking such influences into consideration when assessing the possible effect of breast feeding or other factors on rates of illnesses. Most studies claiming benefit from breast feeding in reducing illness have failed to consider such influences adequately in their analysis.

The retrospective nature of much of the data used in the present study is a possible source of criticism. The large sample size and general representativeness of the population studied, however, might reduce somewhat the effect of variation in parental recall. Although socially advantaged parents were more likely to report eczema and hay fever in their children, they were less likely to report wheezing or

$$
33184
$$


bronchitis. ${ }^{37}$ The association between breast feeding and eczema shown in this study remained statistically significant even after allowing for variation in socioeconomic status. The association was also independent of family history of eczema or asthma or both. Epidemiological studies, using a standard questionnaire and collecting a wide variety of information avoid the problem of bias, which creates a major difficulty in interpreting the results of most reported studies, where eczema was diagnosed by investigators who almost invariably knew the feeding history.

This appears to be the first study investigating the possible influence of breast feeding on the likelihood of hayfever. There was no association after allowing for confounding factors. In conjunction with our inability to show any association between breast feeding and asthma, it makes the finding of a positive association with eczema the more convincing and disturbing.

The diagnosis of eczema, especially reported eczema in epidemiological studies, is contentious..$^{38-40}$ Papa thinks that the term has little diagnostic validity and suggests that many children with itchy, dry, red, scaly patches of skin may have asteatoic or xerotic eczema due to washing with deodorant soaps containing halogenated salicylanilide compounds rather than atopic dermatitis. ${ }^{39}$ Breast feeding mothers may wash their children more often than mothers who do not breast feed. We have no way of knowing what the actual diagnosis was in the "eczema" cases in our study. Rates of eczema, however, in our children, $17.0 \%$ where there was a parental history of eczema or asthma or both and $9.6 \%$ where there was not, compare with $23.7 \%$ and $13.0 \%$ in a similar study from New Zealand ${ }^{12}$ where the treatment administered was used as a partial validation of the general practitioner diagnosis ${ }^{41}$ and $22 \cdot 1 \%^{42}$ and $12.3 \%^{34}$ in a Swedish survey where eczema (atopic dermatitis) was diagnosed by a paediatrician. Our results would appear to underestimate rather than overestimate eczema (presumed atopic dermatitis).

This study confirms the importance of considering intervening factors before inferring cause and effect relationships from associations such as breast feeding and illness in children. When allowance was made for social and biological factors influencing the likelihood both of breast feeding and of illness, breast feeding itself appeared to have no influence on the atopic respiratory disorders, hayfever, asthma, and wheezing or on other lower respiratory illnesses. ${ }^{37}$ The increased likelihood of eczema being reported in breast fed children, which persisted even after allowing for possible confounding influences, needs confirmation in other populations but raises the possibility that substances harmful to the child are present in breast milk.

The Child Health and Education Study five year follow up was funded by a project grant from the Medical Research Council to the department of child health of the University of Bristol. Additional financial support was received from Action for the Crippled Child and from the National Birthday Trust Fund. We gratefully acknowledge the cooperation of area health authorities, health boards, and health visitors througout England, Scotland, and Wales and the contributions of previous CHES survey workers to the research. BT and JW(in part) are supported by the Riyadh Al Kharj Hospital Programme, Saudi Arabia.

\section{References}

${ }^{1}$ Grulee CG, Sanford HN. The influence of breast and artificial feeding on infantile eczema.J Pediatr 1936; 9: 223-5.

${ }^{2}$ Matthew DJ, Taylor B, Norman AP, Turner MW, Soothill JF. Prevention of eczema. Lancet 1977; i: 321-4.

${ }^{3}$ Chandra R. Prospective studies of the effect of breast feeding on incidence of infection and allergy. ActaPaediatr Scand 1979; 691-4.

4Saarinen UM, Kajosaari M, Blackman A, Siimes MA Prolonged breastfeeding as prophylaxis for atopic disease. Lancet 1979; ii: 163-6.

${ }^{5}$ Kaufman HS, Frick OL. Prevention of asthma. Clin? Allergy 1981; 11: 549-53.

${ }^{6}$ Juto P, Moller C, Engberg S, Bjorksten B. Influence of type of feeding on lymphocyte function and development of infantile allergy. Clin Allergy 1982; 12: 409-16.

${ }^{7}$ Halpern SR, Sellars WA, Johnson RB, Anderson DW, Saperstein S, Reisch JS. Development of childhood allergy in infants fed breast, soy or cow milk.J Allergy Clin Immunol 1973; 51: 139-51.

${ }^{8} \mathrm{Kjellman}$ NIM, Johansson SGO. Soy versus cows' milk in infants with biparental history of atopic disease: development of atopic disease and immunoglobulins from birth to four years of age. Clin Allergy 1979; 9: 347-58.

'Hide DW, Guyer BM. Clinical manifestations of allergy related to breast and cows' milk feeding. Arch Dis Child 1981; 56: 172-5.

${ }^{10}$ Kramer MS, Moroz B. Do breast feeding and delayed introduction to solid foods protect against subsequent atopic eczema? J Pediatr 1981; 98: 546-50.

${ }^{11}$ Gordon RR, Noble DA, Ward AM, Allen R. Immunoglobulin $\mathrm{E}$ and the eczema-asthma syndrome in early childhood. Lancet 1982; i: 72-4.

${ }^{12}$ Fergusson DM, Horwood LJ, Beautrais AL, Shannon FT, Taylor B. Eczema and infant diet. Clin Allergy 1981; 11: 325-31.

${ }^{13}$ Fergusson DM, Horwood LJ, Shannon FT. Risk factors in childhood eczema. J Epidemiol Community Health 1982; 36: 118-22.

${ }^{14}$ Glaser J, Johnstone DE. Prophylaxis of allergic disease in the newborn. JAMA 1953; 153: 620-2.

${ }^{15}$ Johnstone DE, Dutton M. Dietary prophylaxis of allergic disease in children. $N$ Engl J Med 1966; 274: 715-9. 
${ }^{16}$ Mueller JL, Weiss WK, O'Leary D, Murray AB. The incidence of milk sensitivity and the development of allergy in infants. $N$ Engl J Med 1963; 268: $1220-4$.

${ }^{17}$ Brown EB, Josephson BM, Levine HS, Rosen MA. A prospective study of allergy in a paediatric population. Am J Dis Child 1969; 117: 693-8.

${ }^{18}$ Dannaeus A, Johansson SGO, Foucard T. Clinical and immunological aspects of food allergy in childhood. Acta Paediatr Scand 1978; 67: 497-504.

${ }^{19}$ Williams HE, McNichol KN. Prevalence, natural history and relationship of wheezy bronchitis and asthma in children. An epidemiological study. Br Med J 1969; iv: 321-5.

${ }^{20}$ Jones RS. Asthma in children. London: Edward Arnold, 1976.

${ }^{21}$ Leeder SR, Corkhill RT, Irwig LM, Holland WW, Colley JRT. Influence of family factors on asthma and wheezing during the first five years of life. BrJ Prev Soc Med 1976; 30: 213-8.

${ }^{22}$ Chamberlain R, Chamberlain G, Howlett B, Claireaux A. British births 1970. Vol 1. The first week oflife. London: Heinemann, 1975.

${ }^{23}$ Chamberlain G, Phillipp E, Howlett B, Masters K. British births 1970. Vol 2. Obstetric care. London: Heinemann, 1978.

${ }^{24}$ Osborn AF, Morris AC. The rationale for a composite index of social class and its evaluation. Br J Sociol 1979; 30: $39-60$.

${ }^{25}$ Cox DR. The analysis of binary data. London: Methuen, 1970.

${ }^{26}$ BMDP. Biomedical computer programs $P$ series. Berkeley: University of California Press, 1979.

${ }^{27}$ Cogswell JJ, Alexander J. Breast feeding and eczema/asthma. Lancet 1982; i: 910.

${ }^{28}$ Rogan WJ, Bagniewska, Damstra T. Pollutants in breast milk. N Engl J Med 1980; 302: 1450-3.
${ }^{20}$ Talbot FB. Eczema in childhood. Med Clin N Am 1918; 1 : 985-96.

${ }^{30}$ Shannon WR. Demonstration of food proteins in breast milk by anaphylactic experiments on guinea pigs. $\mathrm{Am} \mathrm{J}$ Dis Child 1921; 22: 223-31.

${ }^{31}$ Gerrard JW. Allergy in breast-fed babies to ingredients in breast milk. Ann Allergy 1979; 42: 69-72.

32 Warner JO. Food allergy in fully breast-fed infants. Clin Allergy 1980; 10: 133-6.

${ }^{33}$ Fergusson. DM, Horwood LJ, Shannon FT, Taylor B. Breast feeding, gastrointestinal and lower respiratory illness in the first two years. Aust Paediatr J 1981; 17: 191-5.

${ }^{34} \mathrm{Kjellman}$ NIM. Predictive value of high IgE levels in children. Acta Paediatr Scand 1976; 65: 465-71.

${ }^{35}$ Douglas JWB, Blomfield JM. Children under five. London: Allen and Unwin, 1958.

${ }^{36}$ Spence J, Walton SW, Miller FJW, Court SDM. $A$ thousand families in Newcastle upon Tyne. London: Oxford University Press, 1954.

${ }^{37}$ Taylor B, Wadsworth J, Golding J, Butler N. Breast feeding bronchitis and admissions for lower respiratory illness and gastroenteritis during the first five years. Lancet 1982; i: 1227-9.

${ }^{38}$ Midwinter RE, Moore WJ, Soothill JF, Turner MW, Colley JRT. Infant feeding and atopy. Lancet 1982; i: 339.

${ }^{39}$ Papa CM. Breast feeding and eczema/asthma. Lancet 1982; i: 911.

${ }^{40}$ Atherton DJ. Eczema and infant diet. Clin Allergy 1982; 12: 435

"Fergusson DM. Eczema amd infant diet. Clin Allergy 1982; 12: 436-7.

${ }^{42} \mathrm{Kjellman}$ NIM, Johansson SGO. IgE and atopic allergy in newborns and infants with a family history of atopic disease. Acta Paediatr Scand 1976; 65: 601-7. 